\title{
What Does the Future Hold? A Critical View of Emerging Information and Communication Technologies and Their Social Consequences
}

\author{
Bernd Carsten Stahl \\ Centre for Computing and Social Responsibility, Department of Informatics, \\ De Montfort University, Leicester, UK \\ bstahl@dmu.ac.uk
}

\begin{abstract}
This paper provides an overview of emerging information and communication technologies (ICTs) that can be expected to become socially relevant in the next 10 to 15 years. It describes the results of a dual discourse analysis of publiccations on emerging ICTs. Sources were, on the one hand, government/policy publications and, on the other, publications by research institutions. This discourse analysis led to the identification of 11 emerging ICTs. For each of these ICTs, defining features were collected. In order to gain a larger scale understanding, the defining features were then regrouped to assess which likely effect they might have on the relationship between humans and their environment. These features are then interpreted and investigated with regard to what they betray about the implied assumptions about individuals, society and technology. The paper ends by critically reflecting the chosen approach and asking how this research can help us develop technology in desirable ways.
\end{abstract}

Keywords: Emerging ICT, methodology, social consequences.

\section{Introduction}

Narratives of changes in the way we live based on information and communication technologies (ICTs) abound. One can frequently hear references to an information "revolution," which would seem to imply that such technologies fundamentally change the way we live (Floridi 2007). The revolution metaphor is taken up and intensified by commercial interests, which emphasize the significance of changes of consumer products. This view of ICT as revolutionary is linked to a wide-spread perception of an increase in the speed of life. Personal lives become more variable in some respects but also more constrained as more choices are offered and communication is increased.

The present paper takes these perceptions as a backdrop and asks what the future of ICTs may be. Are there ways of gaining a better understanding of emerging ICTs and, if so, can we paint a picture of the future of such technologies that gives an indication of what consequences these emerging technologies have for our lives? 
This paper justifies, describes, and critically interprets some tentative answers to the question of what information technologies are likely to emerge. Based on the European research project ETICA (Ethical Issues of Emerging ICT Applications), the paper describes one possible way of identifying emerging ICTs and explains the methodology used to implement it. It then outlines the findings and briefly characterizes those technologies that were identified as probable and reasonable candidates to emerge in the next decade or so. The paper constitutes one of the outputs of the ETICA project, which aims to identify emerging ICTs and their ethical aspects in order to develop recommendations on how best to address them. The paper only touches on the initial outcomes of the ETICA project, namely on the identification of ICTs and their implications.

On the basis of this characterization of individual ICTs, the paper then provides a synthesis of the overall technical environment that would arise from these technologies. In the conclusion, the paper will return to the opening paragraph and speculate on societal trends that may arise from the possible future described here.

The main contribution of the paper is that it offers an overview of the ICT landscape that we have reason to expect to emerge in the next 10 to 15 years. The paper goes beyond the more frequent approach of describing and analyzing individual technologies or problem areas. It attempts to draw a larger picture and explore the characteristics of technology-enabled societies in the medium term future. Such an endeavor is by nature and necessity fallible and unlikely to provide an exact prediction of the future. It is nevertheless important because it draws a picture of the way we currently imagine the future, which is important if we now want to make the right decisions, both in terms of technology and policy development, to lead to the society in which we collectively wish to live.

\section{Emerging ICTs}

It may be too obvious to state, but in order to avoid misunderstandings, it may be necessary to underline that we do not know the future. The future is fundamentally characterized by being unknown and unknowable. But, of course, things do not stop there. Humans' desire to know the future is probably as old as humanity. In addition, there are reasons to believe that some aspects of the future are predictable and, in fact,

Table 1. Research-Related Problems Encountered in Describing Emerging ICTs

\begin{tabular}{|c|c|}
\hline Problem & Description \\
\hline Conceptual Issues & $\begin{array}{l}\text { Lack of clarity of all constituent terms, for instance, } \\
\text { - } \quad \text { Emergence } \\
\text { - } \quad \text { Information } \\
\text { - } \quad \text { Technology }\end{array}$ \\
\hline $\begin{array}{l}\text { Approach and Methodology } \\
\text { Scientific justification of the } \\
\text { methodology used to identify } \\
\text { emerging ICTs }\end{array}$ & $\begin{array}{l}\text { - Uncertainty of the future } \\
\text { - } \quad \text { Purpose of investigations of futures studies } \\
\text { - } \quad \text { Sources of knowledge about the future } \\
\text { - } \quad \text { Justification of chosen sources over others }\end{array}$ \\
\hline
\end{tabular}


much of the organization of societies is based on this predictability of the future. Commercial and administrative activities rely on recurrence of activities, usually rightly so. To some degree this predictability extends to technologies.

Research on emerging ICTs has to contend with numerous problems. Table 1 summarizes the core problems that were encountered in this paper.

It is not the purpose of this paper to go into much depth in these problems, which are described in more depth elsewhere (Stahl et al. 2010). It will be necessary, however, to briefly outline how they were addressed in order to render the subsequent description of technologies comprehensible.

\subsection{Conceptual Issues}

Each of the constituent terms of emerging information and communication technology is worthy of detailed analysis in its own right. The term emergence, for example, has a long history in philosophy and can be found in a number of other disciplines. Very briefly, it can be understood as a counterpoint to linear and predictable developments. Emergent phenomena are not easily predictable but develop from the interaction of components of a system. Given this position, it is almost a contradiction in terms to do research to determine emerging technologies. They defy easy recognition by definition. There are, however, differences in certainty of knowledge about emerging issues that are related to the temporal horizon in which they are investigated. For the purposes of the present paper, emerging technologies are defined as those technologies that have the potential to gain social relevance within the next 10 to 15 years. This means that they are currently at an early stage of their development process. At the same time, they have already moved beyond the purely conceptual stage. This will become obvious later during the introduction of the technologies that were identified, most of which already have social presence, are to some degree already established. Despite this, these emerging technologies are not yet clearly defined. Their exact forms, capabilities, constraints, and uses are still in flux.

A similar conceptual problem is raised by the term technology. This paper cannot engage in any depth with the philosophy of technology (Dusek 2006; Olsen et al. 2009). Characteristics of technology that one can typically find include a basis in structured thought, temporal stability, and reproducibility, and a reflection in artefacts which may be (but do not have to be) of a physical nature. Technologies are typically developed for specific ends.

An important issue related to the concept of technology is the question of interpretive flexibility. Interpretive flexibility denotes the property of technology of being constituted by use. It is a position that is opposed to technological determinism, which holds that technology has an observer-independent reality and will have clear and predetermined uses and applications. Proponents of interpretive flexibility argue that technology is not fixed but will develop during perception and use. The tenets of interpretive flexibility are widely recognized in science and technology studies where different positions such as the social study of technology (SST) or the social construction of technology hold such views (Bijker 1997; Grint and Woolgar 1997; Howcroft et al. 2004) and also in related fields such as actor-network theory (Latour 2007; Law and Hassard 1999). Some scholars distinguish between interpretive and interpretative flexibility, with the former referring to the epistemological aspect of the social 
construction of technology and the latter being a stronger position that sees the construction as ontologically constitutive of technology (Cadili and Whitley 2005).

There is a direct link between emergence and interpretive flexibility. Interpretive flexibility is a function of social interaction and pertains to particular discourses. That means that a technology may emerge in one context even though it may well be established elsewhere. It also means that the same underlying artefact can emerge into different technologies in terms of usage and application. Interpretive flexibility is connected to the social meaning of a technology, which requires researchers to avoid the technical determinist position and to consider the political and social framing of technological meaning.

For the purposes of the present paper, the term technology was defined as being on a high and abstract level. A technology in this sense of the word is a high-level system that affects the way humans interact with the world. This means that one technology in most cases can comprise numerous artefacts and be applied in many different situations. It needs to be associated with a vision that embodies specific views of humans and their role in the world.

An example may help explain this. One core technology that has been widely described and researched is that of ambient intelligence (AmI). AmI is characterized by a number of defining features such as embeddedness, interconnectedness, invisibility, adaptivity, and personalization, among others. This technology implies a view of the world in which humans require and desire support, are seamlessly connected, and have an adaptive environment. To realise this vision, numerous artefacts such as sensors, networks, and algorithms can be used. The technology does not depend on any one of these to become reality.

The final conceptual issue to be touched upon is that of the delimitation of information and communication technologies. There is no clear and unambiguous definition of ICT. The terms information and communication are as complex as technology. Concentrating on ICT does rule out a substantial number of potential technologies, but it leaves a large number. In addition, one can observe initiatives to realize the convergence of ICT with other technologies, notably biotechnology, nanotechnology, and cognitive technologies (also called NBIC technologies) ${ }^{1}$.

\subsection{Approach: Principles of Technology Foresight}

Knowing the meaning of emerging ICTs does not imply a particular way of finding out which technologies fall under the concept. This raises the question of whether it is possible to find methodologies that are capable of providing information about emerging ICTs. This, in turn, raises the question of which truth claims are to be associated with research on such technologies.

It was already stated that no absolute truth claims about the future are possible. But what can be the purpose of future-related research? One way of answering this question is to move away from the idea of one determined future to a multiplicity of possible futures. Cuhls (2003) uses the term foresight instead of forecasting in order to

\footnotetext{
${ }^{1}$ The 2009 conference of the Society for Technology and Philosophy was dedicated to the topic of these converging technologies (see http://www.utwente.nl/ceptes/spt2009/).
} 
underline the difference between one-dimensional and multidimensional views of the future. The present paper can be understood as foresight research in this sense. What is the purpose of foresight research? What can it achieve? A main purpose of this type of research is to explore possible futures with a view to identifying and selecting desirable ones that can then be pursued. This selection is then investigated with regard to its implications for today. As a final step, decisions can be made today that influence the outcome of the future options. The aim of foresight activities is not to describe one true future but some or all of the following (Cuhls 2003):

- To enlarge the choice of opportunities, to set priorities, and to assess impacts and chances

- To prospect for the impacts of current research and technology policy

- To ascertain new needs, new demands, and new possibilities as well as new ideas

- To focus selectively on economic, technological, social, and ecological areas as well as to start monitoring and detailed research in these fields

- To define desirable and undesirable futures

- To start and stimulate continuous discussion processes

These aims underpin the present research. The subsequent outline of the chosen methodology as well as the discussion of findings and extrapolation of emerging ICTs should be interpreted in this light.

\subsection{Methodology, Data Collection, and Analysis}

In light of the general justification of the approach, the steering committee of the project decided that the most useful way to determine emerging ICTs was to analyze discourses that could claim to have good insight or influence on the way emerging ICTs are being shaped. The steering committee is the main body for making day-today decisions in the project. It consists of the leader of each of the work packages involved in the project. All of the work described in this paper was undertaken by different members of the consortium. Nations involved include Finland, The Netherlands, the United Kingdom, Belgium, Germany, Hungary, Sweden, and Poland. The composition of the consortium was chosen to fairly represent most areas of the European Union. In terms of subject expertise, the individuals working on the project included philosophers, social scientists, and technologists.

In order to gain a comprehensive coverage of the current understanding of emerging ICTs, two discourses were explored: governmental and policy discourses, in particular those discourses relating to funding plans were included because they substantially shape the agenda of researchers by providing incentives. Documents representing such discourses include national research funding strategies, and funding council publications or the EU calls for proposals under the EU's $7^{\text {th }}$ Framework Programme. The other discourse analyzed was constituted by research institutions' publications. The rationale here was that research institutions are closest to the actual research currently going on, and that they have the best insight into the nature of technologies currently under investigation and thus are best placed to estimate the future of these technologies. 
In a first step, a pilot exercise was undertaken in which all members of the steering committee attempted to identify the description of emerging technologies in three different documents. A meeting was then held to compare the findings. During this meeting, it became clear that a consistent analysis strategy was needed to ensure the reproducibility of the data.

In order to allow a consistent analysis of these two discourses, an analytical grid (see Figure 1) was developed in a bottom-up way. This structure emerged from the initial attempts to identify emerging ICTs from documents and was shown to be useful in standardizing the collection of data. It is important to understand that the analytical grid is not theory-led but emerged inductively from the data. The rules of analysis were not defined a priori but emerged from the engagement with texts and were then collectively inscribed in the analytical grid and its subsequent implementation in a database.

This structure distinguishes between three main types of entities to be identified and categorized:

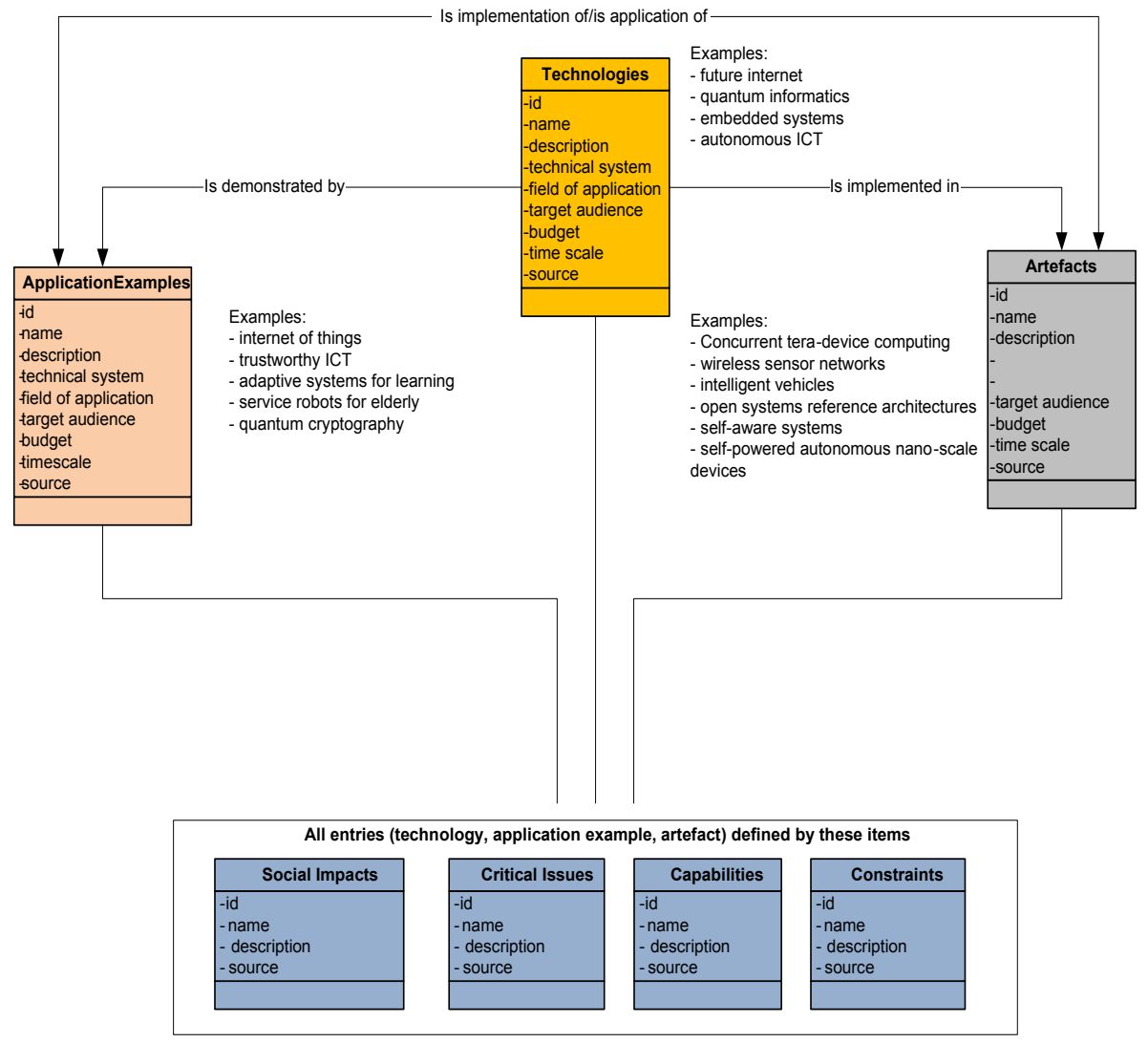

Fig. 1. Analytical Grid for Discourse Analysis 


\section{Technologies (most general, high-level category)}

2. Application examples (the use of technologies in particular contexts)

3. Artefacts (the implementation of the technologies)

The distinction between these three types of entities allowed a concentration on the technologies themselves since these are the main focus of the data analysis. At the same time, it permitted room for the investigation of particular examples, which helped in understanding the nature of the technology, as well as the affordances or issues linked to particular implementations of actual artefacts.

Due to the geographically dispersed nature of the consortium, the steering committee decided to develop a web-based online database to collect data, compare findings, and synthesize the findings. This database was a bespoke database developed on the basis of the analytical grid. It allowed users to input new technologies and categories.

The analyzed documents varied greatly in style, purpose, length, detail, and other aspects. An important problem was, therefore, to ensure consistency and reproducebility of the findings. In order to avoid the injection of bias into the data analysis, it was decided to cross-validate the data analysis. For this purpose, each team member analyzed three different texts. This analysis was then reviewed by and discussed with other team members. The results of these discussions were again captured in a wiki.

It turned out that some of the foreseen problems occurred: there was a lack of agreement on what exactly should count as a technology, application example, or artefact. In addition, analysis by different individuals was done with differing levels of granularity and detail.

Despite these differences in detail, the project team found that the main items and issues were identified in similar ways by different analyzers. Given that it was expected that the data analysis would include a large amount of redundancy (identical technologies being discussed by a number of documents) and that further steps in the project would evaluate and contextualize findings, it was decided that the approach was sufficiently robust to provide the results expected, namely an identification of technologies as viewed by discourses on emerging ICTs.

\section{A View of Emerging ICTs}

The consortium identified 27 different documents worth analyzing. The criteria for identifying and including documents were that they had to belong to one of the discourses of interest to the research, they had to clearly discuss emerging ICTs, this discussion had to be sufficiently detailed to allow the collection of relevant detail about the technology, and they had to be accessible to the consortium. Data collection was stopped when theoretical saturation was reached (i.e., when no more new items were identified).

The analysis of the texts led to the identification of 107 technologies and 70 applications. A more detailed look at the lists revealed that there was considerable overlap. In addition, there were items on the artefacts list that were not covered elsewhere.

It was, therefore, decided to group the technologies, applications, and artefacts in a way that would correspond with the earlier definition of technology as a high-level 
and abstract concept that is sensitive to the way humans interact with the world. The aim was to identify those technologies that are at a high level of abstractness and that would cover the applications, artefacts, and contributing technologies.

The initial list of 107 technologies was regrouped, ordered, and categorized to allow the most important high-level technologies to remain, whereas component technologies were subsumed into these high-level technologies. This left a list of about 20 technologies. Several rounds of discussion among project team members and consultation with external experts followed. These external experts were individuals who were knowledgeable in the individual technologies listed in Table 2 . They were not members of the consortium and did not receive any remuneration for their involvement. Their main task was to critically review the descriptions of the technologies in order to ensure that these descriptions did not contain factual inaccuracies. During discussions within the consortium and with the external experts, further technologies were eliminated because they were perceived to be applications rather than technologies, did not offer an insight in the underlying vision of the relationship of humans and the world, or because they fell outside the ICT remit of the study. The end result of this process is the list of technologies presented in Table 2.

Table 2. List of Emerging ICTs

\begin{tabular}{|l|}
\hline Affective Computing \\
\hline Ambient Intelligence \\
\hline Artificial Intelligence \\
\hline Bioelectronics \\
\hline Cloud Computing \\
\hline Future Internet \\
\hline Human-Machine Symbiosis \\
\hline Neuroelectronics \\
\hline Quantum Computing \\
\hline Robotics \\
\hline Virtual/Augmented Reality \\
\hline
\end{tabular}

It is important to recapitulate what this list of emerging ICTs represents. It is the result of an analysis of two interlinked discourses on emerging technologies. The claim here is that these are reasonable and robustly determined candidates of ICTs that are likely to have significantly increasing social impact in the next 10 to 15 years. They are thus a good guess of what the future holds in stock and they serve the purpose of reflecting on which futures they will facilitate and which consequences this might represent now.

\section{Features and Consequences of Emerging ICTs}

Having developed a list of emerging technologies, the next challenge was to understand more clearly what these technologies entailed. The project team, therefore, set 
out to determine their core features. These are the features that have a potential to influence the relationship between humans and the world, that can change individual lives or social arrangements. In order to find out what these main features are, the project team went back to the database containing the data analysis and extracted the entries pertaining to the respective technologies. This data was used as a starting point to write a short document characterizing each technology. In order to keep an open mind and avoid initial bias coming from particular interests related to the technology, the technology descriptions were developed from a set of application examples. Where these could be found in the database they were used. Other sources were also perused. These application examples were then used to synthesize definitions and defining features. In addition, broader research literature was then used to supplement these descriptions. The descriptions were completed by outlining related technologies and social consequences. After an internal review, these documents were then sent out to external experts in the particular field of technology to ensure that no substantial mistakes or oversights remained.

The structure of each technology description was thus as follows:

- History of the technology and concepts

- Approximately five application examples

- Defining features of the technology

- Critical issues (i.e., ethical/legal questions, capabilities, and constraints)

The individual technology descriptions are available on the project website at www.etica-project.eu. The purpose of this paper is not to discuss individual technologies or engage in the question of whether the list presented in Table 2 is complete (very unlikely) or still contains redundancies (very likely). Instead, the purpose of this paper is to investigate whether there is a larger picture that can be gleaned from the sum of the technologies. For the purpose of the present paper, it was necessary to find a way to render these descriptions accessible. To achieve this, the defining features of all technologies were collected into a single mind map. Each technology was a node with all defining features being assigned a sub-node. The full text descriptions of the defining features were saved in these nodes, so that the researchers could easily access them but so that they did not show in the main mind map.

As an example, the node of affective computing is presented in Figure 2. Clicking on the notepad icon would reveal the full text description of the technology in question. For the first point, for example, this would read

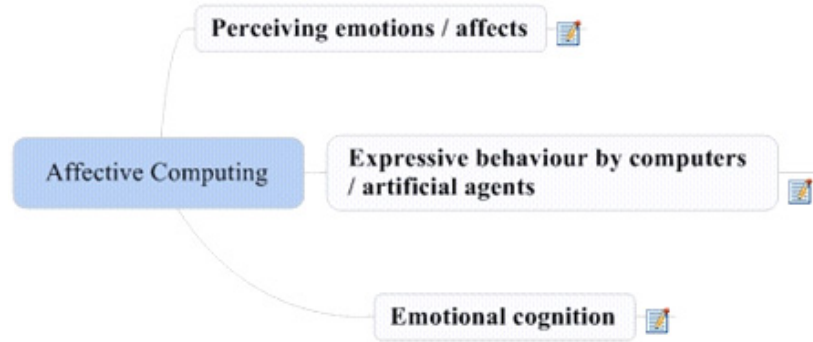

Fig. 2. Mind Map of "Affective Computing" 
Perceiving emotions/affects (i.e., sensing of physiological correlates of affect). The principle here is that humans send signals that allow others to infer the agent's emotional state. Such emotional cues may be with the agent's control, such as tone of voice, posture, or facial expression. They may also be outside the agent's control as in the case of facial color (blushing), heart rate, or breathing. Humans are normally aware of such emotional cues and react easily to them. Most current technology does not react to such emotional cues even though they are part of the illocutionary and perlocutionary function of a speech act.

This was done for all technologies, producing the mind map shown in Figure 3.

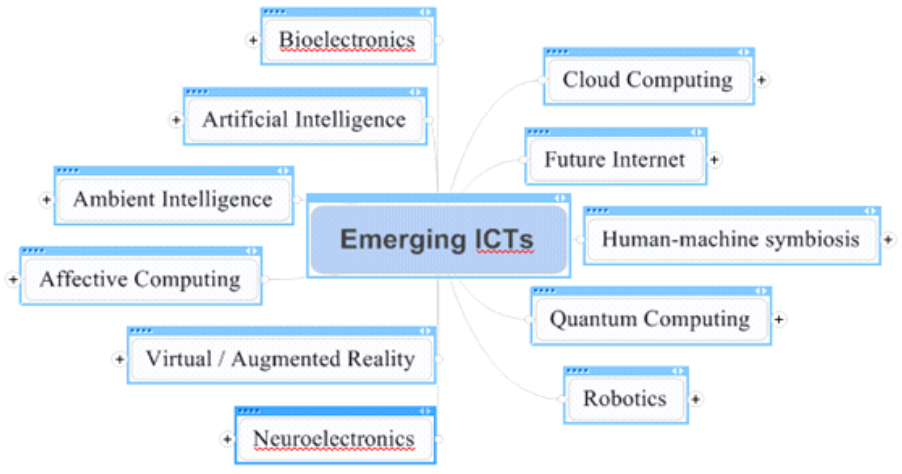

Fig. 3. Mind Map of Emerging ICTs

Expanding to show the defining features of all emerging ICTs results in the map shown in Figure 4.

This overview was then used to regroup the defining features from individual technologies to the more general social consequences or shared assumptions about humans and society they portrayed. The aim of this type of data analysis was to provide an insight into shared, predictable consequences of these different technologies, which would allow for a broader description of how a future society modeled on or involving these technologies would look.

To preempt predictable but unnecessary criticism, we need to state that we are aware of the possible down-sides of this approach. It uncritically accepts descriptions and features of technologies that are still under development. It abstracts from real uses and environments without considering the possible role of human agency, be it in strengthening, changing, or resisting the different technologies and their consequences. Furthermore, it regroups features without deeper regard to the nature of the different technologies, which may lead to combinations of technologies that will never occur.

It is, therefore, important to reiterate what this categorization is meant to represent, namely a view of current discourses on emerging technologies. These discourses are important in that they shape perceptions but also infrastructures and funding that will be used to promote the futures implied in them. Figure 5 should be understood as 
an attempt to graphically represent dominant discourses. Doing so helps us understand the content of expected technologies as well as their implications, which, in turn, is a condition of engaging in any attempt to change them.

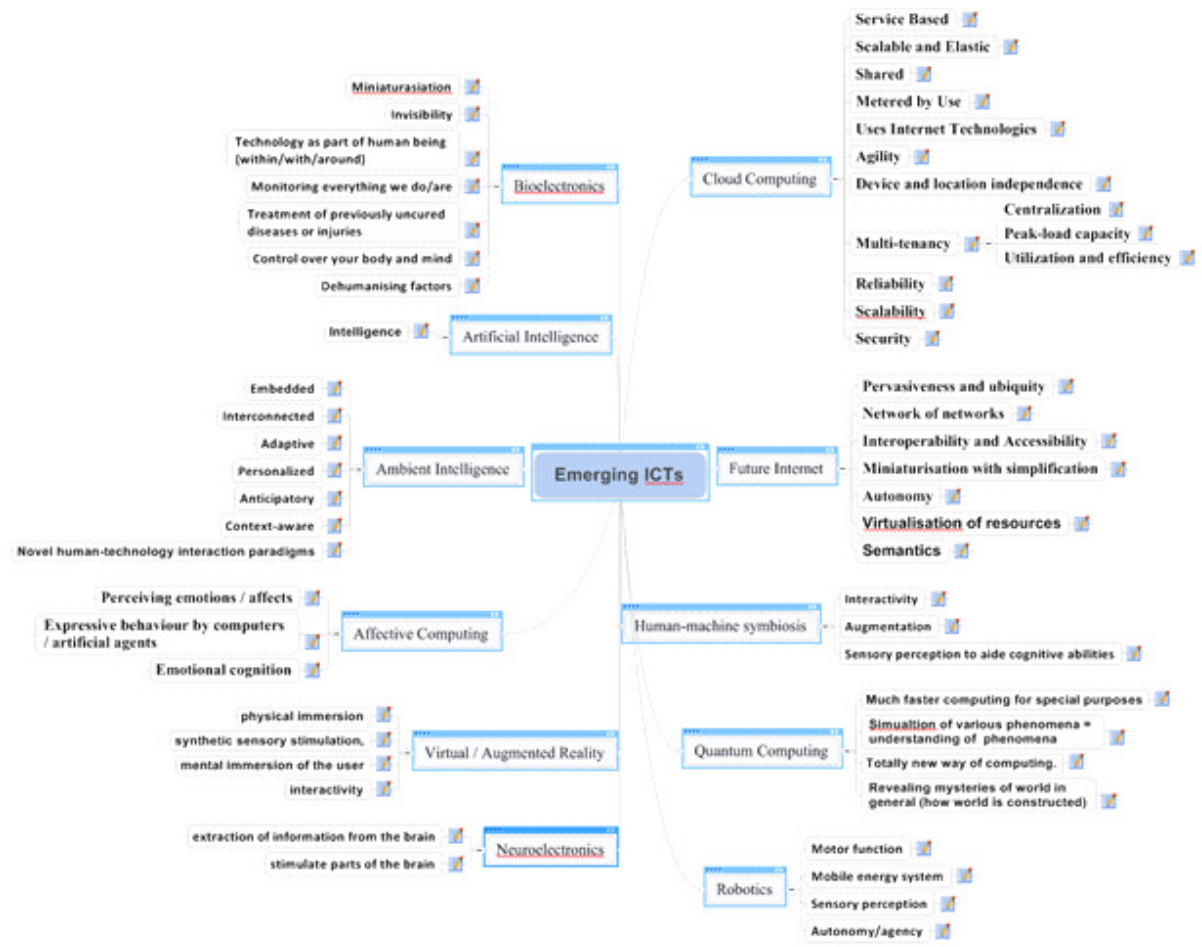

Fig. 4. Defining Features of Emerging ICTs

\section{Description of the Social Consequences of Emerging ICTs}

Figure 5 deserves a closer look and interpretation. This section will briefly explore each of the main term and spell out its relevance and meaning.

Natural interaction is core to many of the emerging ICTs. The idea behind it is to move away from specialist ways of interacting with technical devices, such as mice, keyboards, or screens, to engaging with them in ways with which users are more familiar. The technologies use a number of ways of gathering information about the user that can be intentionally given information but also contextual information or personal information about which the user may not even be aware (as, for example, emotional states). The user will in many cases not even notice that she or he is interacting with a technology that is deeply embedded in the user's environment.

One recurring aspect of this natural interaction is the invisibility of the technology. Technical artefacts recede to the background, making it easy to forget their presence and interacting with users in numerous ways. 

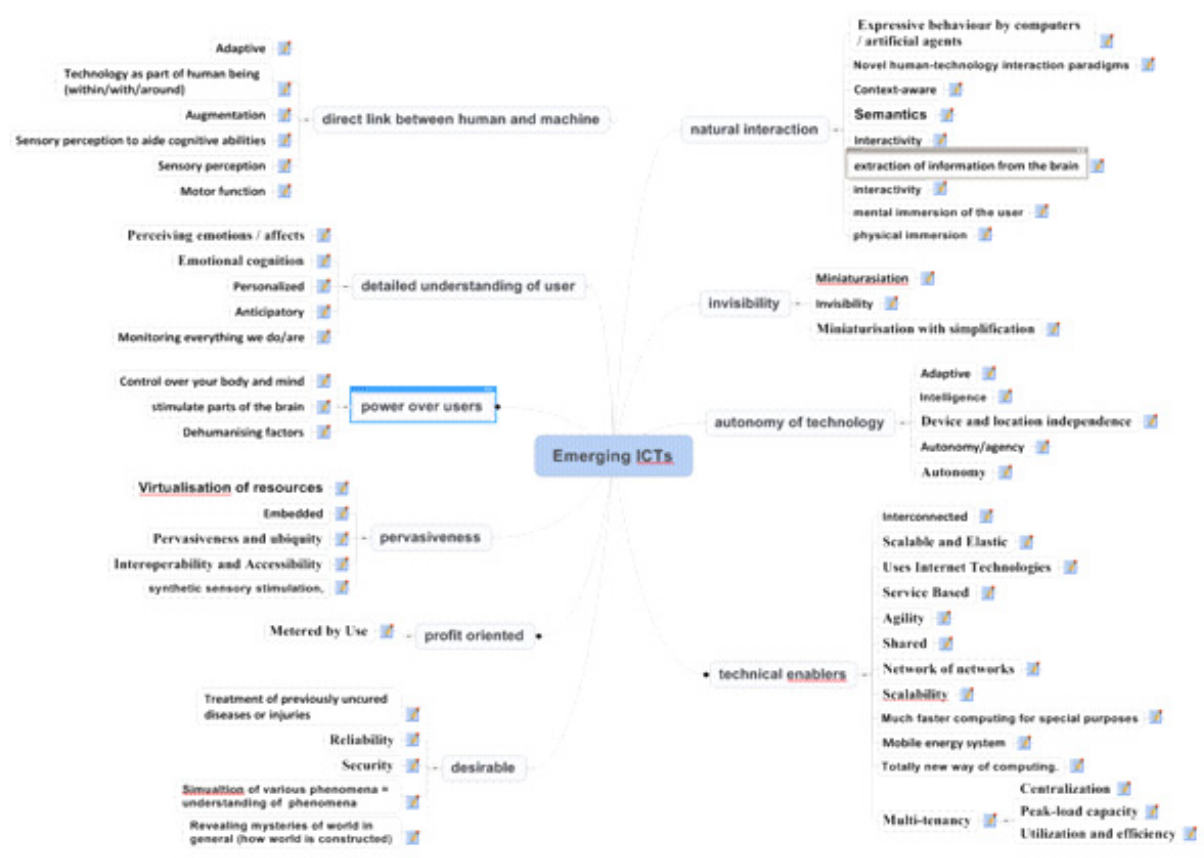

Fig. 5. Social and Socio-Technical Implications of Emerging ICTs

A further aspect of the interaction is the direct link between humans and technology. This can either be physically implemented, as in the case of implants, which can be inserted in the user's body and even their brain. In many cases, the direct link is less intrusive, for example, when the technology continuously surveils the user. This direct link is not only an input device of technology but often has the purpose of supporting and strengthening the user and, in particular, those aspect of the user that are viewed as problematic. Technologies are described as adaptive and augmenting, giving users' greater reach of their natural faculties.

This direct link implies that the technology has a detailed understanding of the user whose needs, wants, and preferences need to be modeled and interpreted correctly for the augmentation and direct link to be successful. This means that bodily, cognitive, and emotional models of the users need to be embedded, which refers back to the natural and invisible interface between user and technology. In order for this to be possible, the technology needs to be pervasive (i.e., embedded in a wide range of environments for the user to be able to profit).

As a consequence, the technology will gain a significant degree of power over the user who will need to rely on the technology and embedded models to accomplish the chores with which that technology is meant to help. In extreme cases-for example, in neurocomputing-a direct link between the technology and the human brain can control not only a person's actions but even their thoughts. But even in less intrusive cases, the technology can easily determine and circumscribe avenues of activity. 
This power is linked to autonomy of the technology, which will be relied upon to make numerous decisions and act proactively in order to achieve its functions. The technology, therefore, needs to be context sensitive, mobile, and intelligent. It correctly interprets the user's situation and acts accordingly.

It is important to note that as a general point the different technologies under investigation are described as positive and desirable in their use and consequences. They will allow a better understanding of all sorts of natural and social phenomena. Their aim is to help and support users, in particular in those cases where they find it hard to fend for themselves (e.g., in cases of disability or disease).

In Figure 5, several defining features of different technologies were collected under the heading technical enablers. These are aspects of the technologies that are deemed to be necessary to fulfil the functions of the technologies. For space reasons, these are not investigated in more detail here, even though this would doubtlessly be an interesting further task. We will finish this brief attempt to outline the main sociotechnical consequences of the emerging ICTs and move toward a reflection of the assumptions, beliefs, and models that underlie them.

\section{Critical Interpretation of the Social Consequences of Emerging ICTs}

It may be advisable to start this section with another caveat. Of course the very brief outline of characteristics of emerging technologies in the previous section does not do the technologies justice, nor does it reflect the richness of the descriptions and visions from which they were extracted. Their purpose was to give a basis for the following critical analysis, which will provide a deeper insight into the background and content of the visions of emerging ICTs. These will be split into assumptions about individuals, society, and technology.

\subsection{Assumptions about Individuals}

The emerging ICTs described above all make explicit or implicit assumptions about the individuals that will use them. Many of these assumptions can easily be deduced from the defining features of the technologies. They are, however, rarely critically reflected and in many cases will find it hard to stand up to scrutiny.

A first assumption about users is that they have particular needs that the technology can fulfil and that they are able and willing to recognize this and make appropriate use of the technology. This may be true of any technology description but it is particularly obvious for these emerging ICTs. It is also empirically questionable given the nature of some of the technologies described.

A further characteristic of the individual users is that they can be described in terms that are conducive to the use of the technology. This implies an objectivist and positivist view of humans. The technologies imply the ability of humans to change but, as a general rule, this change is continuous and logically consistent. Such views of individual stable identities have been questioned by numerous researchers from a range of backgrounds. The objectivist anthropological views underlying much of the technology planning also raises questions of feasibility of the visions behind them. 
Such questions include whether human emotions are clearly identifiable, whether human wishes and preferences are consistent and logical, how technology can deal with human inconsistency and self-contradictions, to name just a few.

An important further aspect of the view of humans is related to the question of autonomy. Autonomy is a thorny philosophical concept in its own right, touching on questions of ethics, of freedom of will and of action. With regard to emerging ICTs it is notable that autonomy is an attribute that is increasingly attributed to ICTs. These act autonomously (i.e., without direct input from users). There is an interesting assumption that users are not only comfortable with this but even actively desire it. Such autonomy of ICTs can arguably conflict with the autonomy of users but this issue is not normally explored in descriptions of the technologies.

Summarizing, one can say that the view of humans in relation to the discourses surrounding emerging ICTs explored for this research is rather one-dimensional. Humans are viewed as predictable users with consistent needs and preferences. Rejection or resistance of technologies is generally not expected or foreseen. Based on this simplistic view of humans, a comparable view of society is typically implied.

\subsection{Assumptions about Society}

Society is rarely explicitly mentioned in discourses on emerging technology, beyond rhetorical references to the importance of the particular technology in meeting societal goals. What can be learned about what the proposers of the technologies think about the society in which it will be used and how it will influence this society tends to be indirect.

An important observation that can be deduced from this is that society is generally not seen as a particularly important aspect of the development and use of emerging ICTs. It is seen as a relatively static background that can allocate resources and regulate but generally has no major role to play. There is an assumption about homogeneity of societies, possibly because technologies tend to be developed for larger markets and across national and cultural boundaries. These boundaries and their implications for technologies are rarely made explicit.

A further background assumption on the societies in which the technologies will be developed and used refers to the socio-economic system. There is typically an implicit belief that the technology will be subject to market forces. Most of the technologies are designed for individual or organizational use and will have to compete with alternative technologies for market share. This view is so pervasive as to become invisible. The fact that there are alternatives to this market-oriented view of society is not reflected. It is worth remembering that, not too long ago, much advanced technology development was state-owned and not related to markets (e.g., nuclear power, military technology).

A final observation on the role of society in emerging ICTs is that the dynamic relationship between these two actors is rarely reflected. A look at the list of technologies and their shared features as developed above indicates that they hold the potential to radically change numerous aspects of society. These range from the nature of work and leisure to notions of ownership and property and political participation. Despite the potentially sweeping changes some of these technologies could induce, the possible consequences for society are rarely discussed. 


\subsection{Assumptions about Technology}

The final set of assumptions worth noting here is about to the nature of technology. As has become clear by now, descriptions of emerging ICTs tend to be simplistic. They display characteristics of technological determinism, where there are assumptions about properties inherent to technology which will lead to predictable use and social outcomes. Individual and social appropriation, redefinition, or resistance are generally not reflected.

Furthermore, there is a general assumption that technology is practically functional, fulfils given needs and desires, and has morally good consequences. A brief look at the technologies mentioned in this paper shows numerous possibilities of undesired effects, side-effects, possibilities of misuse, etc. There are pervasive issues, notably privacy and data protection, but also intellectual property questions that have relevance to all of the candidate technologies. There are, furthermore, less obvious issues that may arise only in particular instances, which nevertheless may shed doubt on the assumption of desirability of the technology.

\section{Critical Reflections}

This paper states in its title that it aims to give a critical review of emerging ICTs. It is thus fitting to end the paper by critically reflecting whether this has been achieved. This will be done by first considering the approach used in the paper and then asking what this can tell us about the future.

\subsection{Critical Reflections on the Approach}

There are numerous potential weaknesses of the approach presented here. Most of them are directly related to the topic area-namely, the future of ICT. As pointed out several times, the uncertainty of the future renders it impossible to give a precise account of what will happen. The chosen approach of using a dual discourse analysis provides the paper with academic rigor but even this does not overcome the principal problem of uncertainty.

The paper could also be accused of being too narrow in its choice of sources. By concentrating on governmental/policy publications on the one hand and statements by research institutions on the other hand, the breadth of discourses does not reflect all possible futures. We argue that these two discourses have the advantage of giving a good account of what is being researched at the moment, but one could of course also aim for a broader view, for example by analyzing media discourses or even fictional ones. This would be desirable in a further step of the research.

There are, furthermore, many other ways of addressing the subject area. The approach presented here is only one way of finding access to our understanding of the future. There are numerous other methodologies of future-oriented research (Georghiou et al. 2008). Following any one of these methodologies might have led to different results or different emphases. In the light of what was said earlier about the nature of foresight research, this is not necessarily a problem for this research. As long as the possible futures analyzed here are plausible, interesting, and allow for a discussion of which future we want to achieve, the approach is justified. 
The critical interpretation of views of humans, society, and technology in the previous section could be accused of lacking nuance and being, to some degree, selffulfilling. Given that the technologies under investigation are at a stage of development that prevents empirical accounts, we have to rely on implicit and simplistic assumptions. Technologists must work with views of their users and these views need to be manageable and be conducive to the development work. Similarly, technology developers are normally not experts and often not particularly interested in the relationship to society.

We would concede this point but argue that it is nevertheless important to tease out what these assumptions are and on what basis technologies are being developed. An easy way of understanding why this is important is to conceptualize a different world, for example, one in which intellectual efforts are not subject to legal protection but open to everyone or one where commercial exchange is not the dominant way of allocating access to technology. Such worlds are at least logically conceivable and the interesting question is whether they would lead to the same technologies. If not, then the question is how decisions on future technologies and, by implication, on future societies are made.

\subsection{Critical Reflections on the Future}

The above description of the social consequences of technology could be criticized as being biased. It is rather dystopian and concentrates on problematic aspects of technologies. This may to some degree reflect the author's prejudices but it is also a consequence of a conscious attempt to counterbalance the typically very positive description of technologies. This is not the only way of categorizing the features of emerging ICTs, but it is one plausible way of doing so. If the reader can agree with this, then it is reasonable to ask whether the vision of the future implied in these technology descriptions is desirable.

The answer to this will be based on personal judgments and not be generalizable. It is not implausible, however, to assume that there are many who do not see these developments as desirable. Do we really want computers and other technologies that recede into the background, become invisible, interact with us in an increasingly human way, and proactively act in ways that we implicitly want them to? To some degree, it might be nice to live in an intelligent environment in which one does not have to remember to turn of the stove and the heating when going out. On the other hand, this may turn into an oppressively comfortable life in which humans become less and less masters of their own present and future as has been described in numerous works of fiction, notably in Huxley's Brave New World (1998).

This question of whether the overall development of these technologies lead to a world in which we want to live brings us to the main contribution of the paper. It raises the question how we, as individuals, as societies, or as humankind, can and want to control the development of technology. The core problem seems to be that technology development is currently very much left to market forces. Markets are not bad per se and one could argue that they have democratic properties and allow widely distributed aggregation of choices which allow them to recognize collective preferences. While this argument is valid to some degree, it runs into general problems of 
markets with regard to lack of information and transparency, which are exacerbated in the case of future technologies, which, by definition, we can know little about.

This paper submits that there should be better ways of democratically controlling the development of technology. And, indeed, there are numerous methods and mechanisms for doing this, such as technology assessment, value-centered design, usercentered design, and many others. The literature in the field of information systems is littered with attempts to integrate more participative methods into technology design.

The value of a study such as this is that it can raise awareness and allow decision makers on different levels to understand which problems may arise. Such awareness can then lead to the employment of a range of methods and approaches to better understand and address them. Or, to put it differently, this paper should be seen as a contribution to a wider discourse with political decision makers as well as technology developers, industry, and users with the aim of better understanding what we currently say about the future, which will hopefully allow us to build a future that we individually and collectively desire.

\section{Acknowledgments}

The research leading to these results has received funding from the European Community's Seventh Framework Programme (FP7/2007-2013) under grant agreement no. 230318.

The author acknowledges the contribution of the members of the consortium without whom this paper could not have been written.

\section{References}

Bijker, W.E.: Of Bicycles, Bakelites, and Bulbs: Toward a Theory of Sociotechnical Change. MIT Press, Cambridge (1997)

Cadili, S., Whitley, E.A.: On the Interpretative Flexibility of Hosted ERP Systems. J. of Strategic Information Systems 14(2), 165-195 (2005)

Cuhls, K.: From Forecasting to Foresight Processes: New Participative Foresight Activities in Germany. J. of Forecasting 22(2/3), 93-111 (2003)

Dusek, V.: Philosophy of Technology: An Introduction. Wiley, New York (2006)

Floridi, L.: A Look into the Future Impact of ICT on Our Lives. The Information Society 23(1), 59-64 (2007)

Georghiou, L., Harper, J.C., Keenan, M., Miles, I., Popper, R.: The Handbook of Technology Foresight: Concepts and Practice. Edward Elgar Publishing Ltd, Cheltenham (2008)

Grint, K., Woolgar, S.: The Machine at Work: Technology, Work and Organization. Polity Press, Cambridge (1997)

Howcroft, D., Mitev, N., Wilson, M.: What We May Learn from the Social Shaping of Technology Approach. In: Mingers, J., Willcocks, L.P. (eds.) Social Theory and Philosophy for Information Systems, pp. 329-371. Wiley, Chichester (2004)

Huxley, A.: Brave New World. HarperCollins Publishers, New York (1998)

Latour, B.: Reassembling the Social: An Introduction to Actor Network Theory. Oxford University Press, Oxford (2007)

Law, J., Hassard, J.: Actor Network Theory and After. Wiley, Chichester (1999) 
Olsen, J.B., Pedersen, S.A., Hendricks, V.F.: A Companion to the Philosophy of Technology. Wiley, Chichester (2009)

Stahl, B.C., Heersmink, R., Goujon, P., Flick, C., van den Hoven, J., Wakunuma, K., Ikonen, V., Rader, M.: Identifying the Ethics of Emerging Information and Communication Technologies: An Essay on Issues, Concepts and Method. International J. of Technoethics 1(4), 20-38 (2010)

\section{About the Author}

Bernd Carsten Stahl is Professor of Critical Research in Technology and Director the Centre for Computing and Social Responsibility at De Montfort University, Leicester, UK. His interests cover philosophical issues arising from the intersections of business, technology, and information, including the ethics of computing and critical approaches to information systems. From 2009 to 2011, he served as coordinator of the EU FP7 research project "Ethical Issues of Emerging ICT Applications" (ETICA) (GA 230318, www.etica-project.eu). 